\title{
Ovary activation correlates with the reproductive potential of honeybee (Apis mellifera) workers if they are in a foreign colony
}

\author{
W. Rojek ${ }^{1}$ (D) $\cdot$ K. Kuszewska ${ }^{1}$ iD
}

Received: 19 October 2021 / Revised: 14 January 2022 / Accepted: 27 January 2022 / Published online: 11 February 2022

(C) The Author(s) 2022

\begin{abstract}
In eusocial Hymenoptera, the laying of male-determined eggs by workers in an unrelated colony can be a powerful strategy for increasing direct fitness benefits. A recent study showed that honeybee rebels, which are workers that develop under queenless conditions and have high reproductive potential, drift to foreign colonies, with a preference for hopelessly queenless colonies, and act as reproductive parasites. In our experiment, by introducing 5-day-old rebels and normal workers into foreign queenright colonies, we discovered that only rebels developed a reproductive phenotype by activating their ovaries. In a similar experiment with 1-day-old workers, neither rebels nor normal workers displayed such a tendency. We suggest that workers' reproductive potential could thus be a key parameter activating the ovaries in not only drifting workers but also workers acting as reproductive parasites. Our results also support the hypothesis that the colony recognition cue probably has an environmental, rather than a genetic, origin.
\end{abstract}

Keywords Intraspecific reproductive parasites $\cdot$ Rebel workers $\cdot$ Ovary activation $\cdot$ Apis mellifera

\section{Introduction}

One of the most prominent features of hymenopteran insect societies is the reproductive division of labour. Typically, queens monopolize reproduction, while workers are facultatively sterile and refrain from reproducing in the presence of the queen (Wilson 1971; Bourke 1988). However, honeybee (Apis mellifera) colonies are vulnerable to exploitation by cheater workers that lay eggs to be reared either in their own colony or in the colony of conspecifics. This latter phenomenon is called intraspecific reproductive parasitism and is fairly common in western honeybees (Neumann and Moritz 2002; Moritz and Neumann 2004; Pirk et al. 2007; Beekman and Oldroyd 2008; Yagound et al. 2017; Kuszewska et al. 2018) and in other Apis species (Paar et al. 2002; Nanork et al. 2005, 2007; Chapman et al. 2009).

In honeybees, workers drift between colonies, and in some apiaries, up to $40 \%$ of the workers in a colony are from foreign nests (Pfeiffer and Crailsheim 1998). Initially, failures in orientation caused by short distances between

W. Rojek

wiktoria.rojek@doctoral.uj.edu.pl

1 Institute of Environmental Sciences, Jagiellonian University, Gronostajowa 7, 30-387 Kraków, Poland colonies in the apiary were thought to be a major factor explaining the presence of nonnatal workers in the colony (Jay 1965; Pfeiffer and Crailsheim 1998). Drifting individuals were expected to be sterile because the pheromones of the queen efficiently inhibit the development of ovaries in workers (Winston 1987). However, another study has shown that workers drifting to queenless colonies have disproportionately higher reproductive success than native individuals (Chapman et al. 2010). The absence of a queen and her pheromones is the most common factor stimulating ovary activation in workers (Winston 1987) and switches off the normal policing mechanisms, which is the removal of worker-laid eggs (Woyciechowski and Łomnicki 1987; Ratnieks and Visscher 1989; Miller and Ratnieks 2001). Consequently, workers that drift to a queenless colony may have a better chance of reproducing than workers that drift to a queenright colony. However, a study by Chapman et al. (2010) showed that drifting workers had no preference for queenless or queenright colonies, suggesting that this phenomenon is the result of mistakes in orientation. Different study results have shown that workers tend to migrate to foreign colonies, with a preference for hopelessly queenless colonies (Yagound et al. 2017). Similar results were obtained by Kuszewska et al. (2018), who studied the intraspecific reproductive parasitism of rebel workers in honeybees. 
Rebel workers are a recently discovered subcaste of honeybee workers characterized by high reproductive potential (Woyciechowski and Kuszewska 2012). In comparison to typical workers, the rebels are more queenlike. They have significantly more ovarioles in their ovaries and larger mandibular and Dufour's glands, but their hypopharyngeal glands, which synthesize and store brood food (Huang and Otis 1989), are underdeveloped (Woyciechowski and Kuszewska 2012; Kuszewska and Woyciechowski 2015). Additionally, studies of rebels have shown that they lay their own male-determined eggs more often than normal workers, even if they remain in a colony with a queen (Kuszewska et al. 2018). The proximate factors of rebel subcaste development are environmental conditions experienced during the larval stage. Rebels develop in the absence of a queen or, more precisely, in the absence of the queen's mandibular gland pheromones (Woyciechowski and Kuszewska 2012; Woyciechowski et al. 2017). Naturally, such individuals occur after swarming, which is the only natural means of colony multiplication (Winston 1987). The ultimate factor explaining the rebel strategy is based on the assumption of inclusive fitness theory (Hamilton 1964) and results from a dramatic decrease in relatedness between the old queen's workers and the new sister queen's offspring after swarming (Woyciechowski and Kuszewska 2012). The high reproductive potential of rebel workers and their tendency to activate ovaries, even in queenright colonies, influences their behaviour and increases the possibility that they will drift to foreign colonies to lay unfertilized eggs. Indeed, rebels are more likely than normal workers not only to drift to foreign colonies but also to prefer colonies that are queenless (Kuszewska et al. 2018). These findings shed new light on intraspecific reproductive parasitism in honeybees; however, the mechanism underlying this strategy is not fully understood.

Obviously, if workers deliberately emigrate to lay eggs in a foreign colony, there must be some signal or cue that varies between colonies that can be perceived by workers. Evidence suggests that honeybees use both the blend of hydrocarbons present on their cuticle (Page et al. 1991; Châline et al. 2005; Zweden and d'Ettorre 2010) and fatty acids (Breed 1998; Breed et al. 2004) for chemical recognition of nest membership. The recognition cues are colony-specific and vary in the relative amount of individual components between colonies (Zweden and d'Ettorre 2010; Vernier et al. 2019). It has been hypothesized that transfer of the recognition cues between colony members occurs via exposure to the comb wax (Breed 1998; Couvillon et al. 2007; Zweden and d'Ettorre 2010). A recent study showed that differences in the chemical profiles of individuals from different honeybee colonies are a result of gut microbiota differences between colonies (Vernier et al. 2020).
Here, we tested whether rebels experimentally introduced into foreign queenright colonies perceive that they are not in a native colony and respond by activating their ovaries more often than normal workers who accidentally enter a foreign colony and behave in a similar way to natal nestmates (Smith and Loope 2016). We expected that rebels with high reproductive potential and a tendency towards intraspecific reproductive parasitism would be more prone to activate their ovaries after entering foreign colonies. The following predictions were tested: (1) foreign rebels have more developed ovaries than native rebels; (2) foreign normal workers do not differ in ovary activation from native normal workers; and (3) foreign and native rebels have more developed ovaries than foreign and native normal workers. Thus, the expected gradient of ovary development was foreign rebels $>$ native rebels $>$ foreign normal workers $=$ native normal workers. We also examined whether workers learn colony recognition cues at the larval stage or as adult bees. Two hypotheses regarding the time of learning the colony recognition cues by workers were tested: (1) condition corresponds to larvalstage-experienced bees, while (2) condition corresponds to adult-stage-experienced bees.

\section{Material and methods}

The research was conducted in May and June 2018 in an experimental apiary at the Institute of Environmental Sciences of Jagiellonian University. Four queenright honeybee colonies with naturally mated queens were studied, each consisting of 20,000-40,000 workers. Each colony was treated in the same way as previously described (e.g. Woyciechowski and Kuszewska 2012; Kuszewska and Woyciechowski 2015), and the experiment was conducted over 2 successive days, with two colonies per day. Initially, rebel and normal workers were reared in all colonies (Fig. 1). For this purpose, the queen was confined to two experimental frames for $24 \mathrm{~h}$ to produce eggs of similar ages (day 0 ). Next, the colony was divided into queenright and queenless subunits, with each subunit containing one experimental frame (day 3). The subunits were reunited when the worker cells on the experimental frames were sealed (day 13), and beginning at that time, the experimental broods experienced the same conditions during their prepupal and pupal stages. Before the first adult workers emerged (day 21), the experimental frames were placed in an incubator in the laboratory $\left(34{ }^{\circ} \mathrm{C}, 90 \% \mathrm{RH}\right) .200$ freshly emerged rebels (developing in a queenless subunit) and 200 normal workers (developing in a queenright subunit) from each experimental frame were marked on the thorax with a spot of paint (Marabu-Brilliant Painter). Afterwards, both rebel and normal workers were assigned to the following experimental groups: (1) introduced to the native colony on the 1 st day of adult life; (2) 


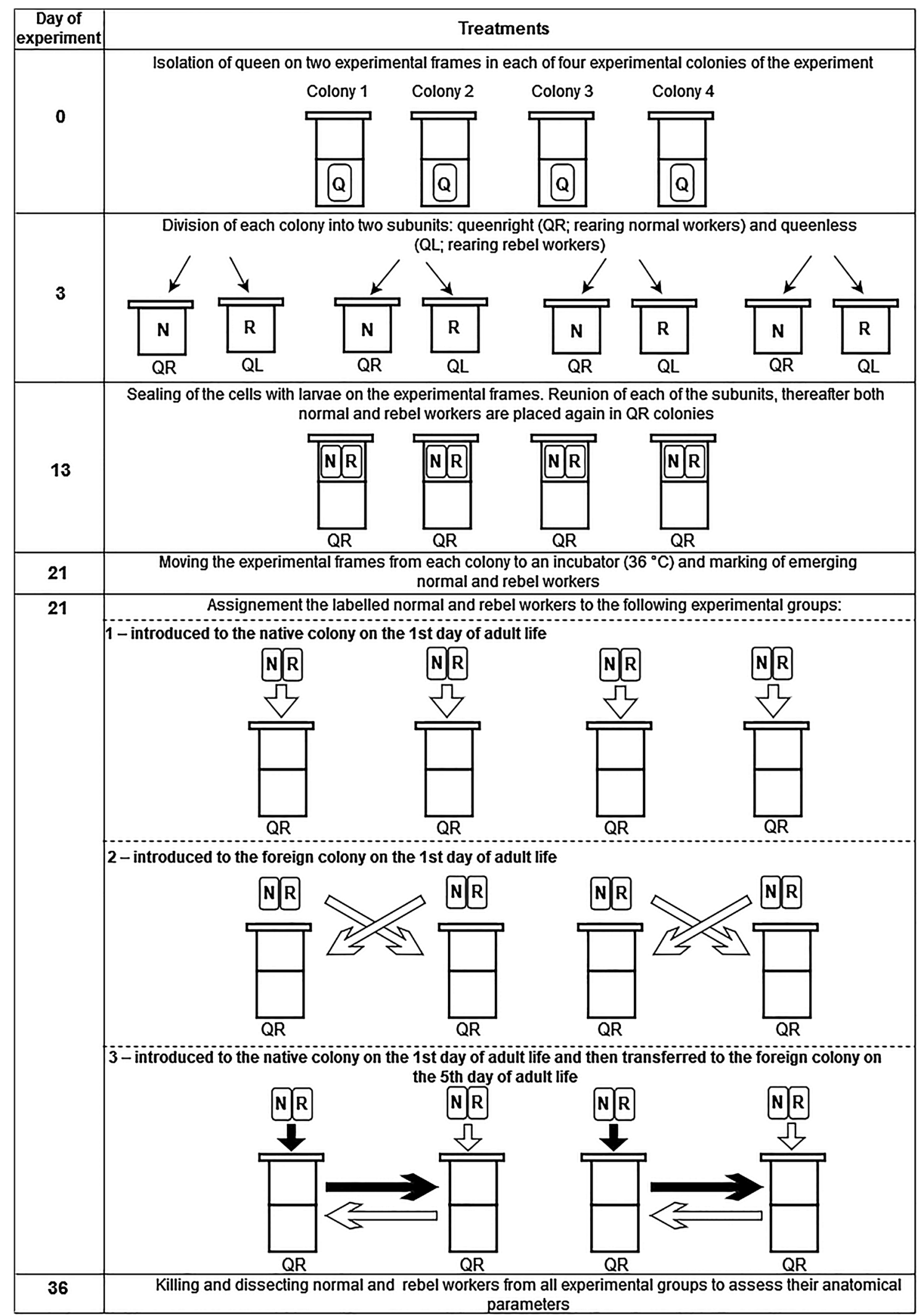

Fig. 1 Timeline of the experiment, showing the manipulations on successive days 
introduced to the foreign colony on the 1st day of adult life; and (3) introduced to the native colony on the 1 st day of adult life and then transferred to the foreign colony on the 5 th day of adult life (Fig. 1). We chose 5-day-old workers for transfer to the foreign colony, as during this time, workers have several days to learn colony recognition cues, but they have not yet begun foraging (Winston 1987). The types of workers (rebels vs. normal workers) and the experimental groups (1-3) were marked with different colours.

When the marked workers were 15 days old, 30 rebels and 30 normal workers were captured from each experimental group (1-3) to assess their number of ovarioles and ovary activation. We dissected the ovaries of the frozen workers and examined them under a stereomicroscope. We counted the total number of ovarioles in both ovaries (sum) and evaluated ovary activation by measuring maximal diameters of the most developed ovariole from each of the ovaries as described by Nakaoka et al. (2008), according to whom ovariole diameter reflects ovarian activity. All organs were stained with Giemsa reagent for approximately $10 \mathrm{~s}$ before being measured.

To compare the number of ovarioles between the rebel and normal workers, a mixed-model three-way ANOVA was used with the type of worker (rebel vs. normal) and the experimental group (1-3) as fixed effects and the colony of origin as a random effect. Statistically significant ANOVA results were followed by multiple comparisons using a post hoc Tukey honest significant difference (HSD) test, with $p<0.05$ considered significant. We used a nonparametric Kruskal-Wallis test to compare the sizes of ovarioles from the two groups of workers and the different experimental groups (1-3) in each of the four colonies. All analyses were performed in Statistica 13.3 (StatSoft, Poland).

\section{Results}

The results showed that rebels, which developed in queenless conditions at the larval stage, had more ovarioles in their ovaries than normal workers (three-way ANOVA, type of worker: $d f=1, F=261.808, p<0.0005$; Fig. 2a), which is consistent with the findings of previous studies (Woyciechowski and Kuszewska 2012; Kuszewska and Woyciechowski 2015; Kuszewska et al. 2018). Neither the colony of origin nor the experimental group (1-3) had a significant effect on the number of ovarioles in workers (three-way ANOVA; colony of origin: $d f=3, F=1.916, p=0.2953$; experimental group: $d f=2, F=0.942, p=0.4404$; Fig. 2a).

There were no differences in ovary activation between workers with different colonies of origin (Kruskal-Wallis test: $p=0.1490)$. Ovarian development depended on the type of worker: rebels had more activated ovarioles than normal workers (Kruskal-Wallis $p<0.0001$; Fig. 2b). Ovary activation did not differ between normal workers from groups introduced to the native and foreign colonies on the 1 st day of adult life ( $p=0.6056)$, and workers from these groups did not differ from those in the group introduced to the foreign colony on the 5 th day of adult life $(p=0.1888$, $p=0.1326$, respectively; Fig. 2b). There were no significant differences in ovary development between rebels from groups introduced to the native and foreign colonies on the 1 st day of adult life ( $p=0.7920)$, but the rebel workers from the group introduced to the foreign colony on the 5th day of adult life had significantly more developed ovarioles than rebels from the groups introduced to the native $(p<0.0001)$ and foreign colonies $(p=0.0058)$ on the 1 st day of their adult life.

\section{Discussion}

In line with our predictions, workers with high reproductive potential, that is, rebels, responded to finding themselves in a foreign queenright colony by activating their ovaries if they had been introduced there on the 5th day of their adult life. In contrast, foreign normal workers, independent of the age at which they were moved, had the same low degree of ovary activation as their natal counterparts regardless of their age. These results suggest that the reproductive potential of workers affects their propensity to activate their ovaries in response to drifting behaviour.

Laying eggs in an unrelated colony can be a powerful strategy for increasing the direct fitness of workers (Beekman and Oldroyd 2008). Recent studies have shown that honeybee workers drift to foreign colonies, with a preference for hopelessly queenless colonies (Yagound et al. 2017; Kuszewska et al. 2018), which implies that acting as reproductive parasites is another option for workers' life strategies. Our study shows that even if rebel workers are experimentally introduced into foreign queenright colonies, they activate their ovaries and presumably invest in personal reproduction in host colonies, while normal workers in the same situation do not. This outcome supports the findings of Kuszewska et al. (2018) that workers with high reproductive potential are more predisposed to function as reproductive parasites. Such behaviour is reasonable because rebels use the resources of unrelated colonies to raise their own male offspring, while their relatives do not bear the cost of caring for their sons.

Unlike rebels, normal workers did not activate their ovaries after being experimentally introduced into foreign queenright colonies. This finding is consistent with that of Smith and Loope (2016), who reported that normal workers entering foreign colonies due to orientation errors continued to refrain from personal reproduction, suggesting that they are caught in an evolutionary trap in which formerly reliable 
Fig. 2 Anatomical parameters of rebels (light violin) and normal workers (dark violin) introduced to the native colony on the 1st day of adult life, a foreign colony on the 1st day of adult life, and a foreign colony on the 5 th day of adult life; shown as violin plots. The white line in the middle of each box plot inset within a violin plot represents the median of each distribution; the white circle inside the box shows the mean; the lower and upper edges of the box represent the first and third quartiles, respectively; and the whiskers represent the 5 and $95 \%$ confidence ranges. The different letters denote significant differences. a The number of ovarioles and $\mathbf{b}$ ovariole size. Data were pooled across all colonies
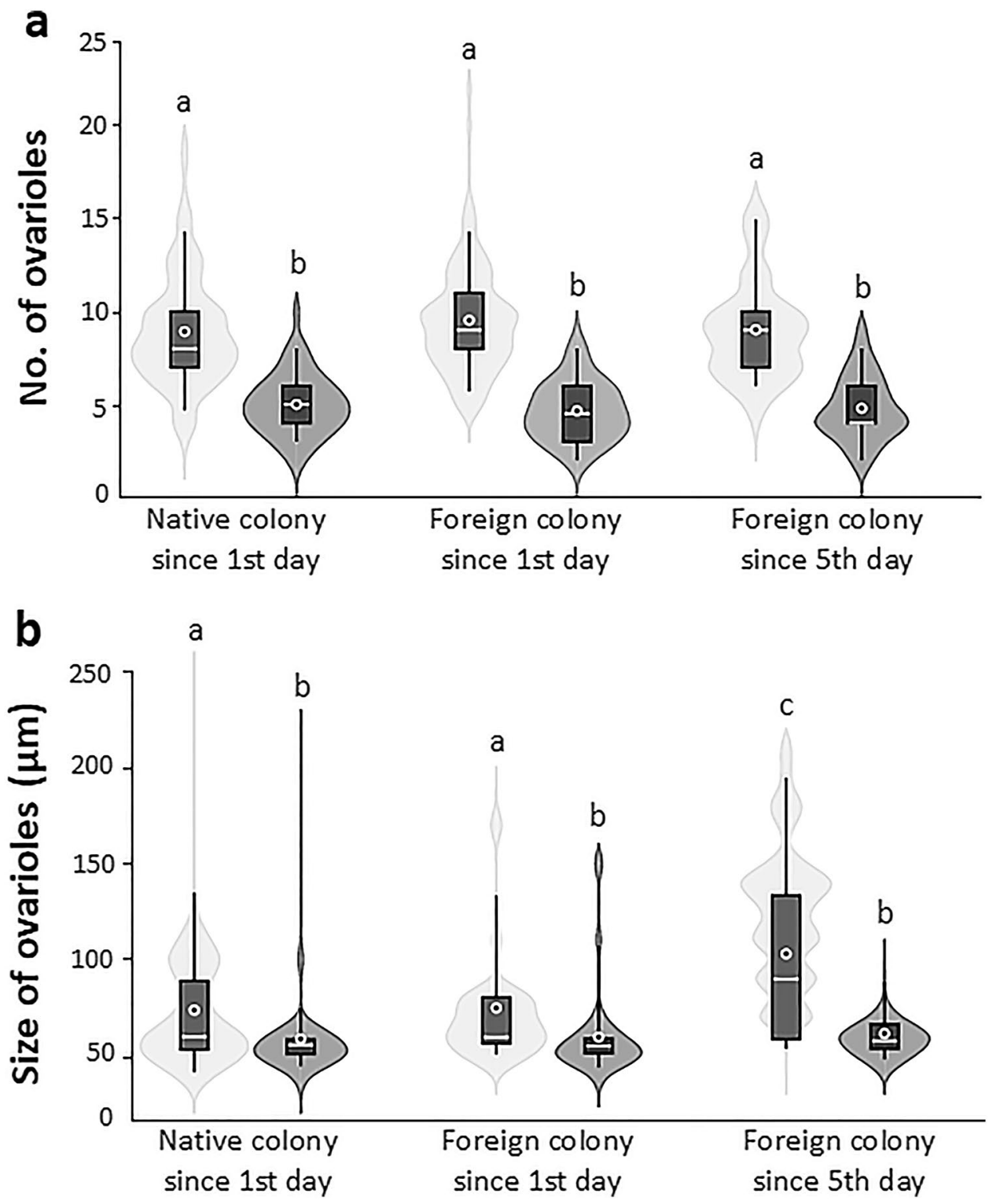

cues no longer lead to an adaptive response (Schlaepfer et al. 2002). In turn, Yagound et al. (2017) showed that the few normal workers that drifted from queenright colonies were significantly more likely to have activated ovaries than their nondrifting natal nestmates. However, in their experiment, unlike ours and that of Smith and Loope (2016), workers followed deliberate reproductive drifting rather than nonreproductive accidental drifting, which are quite different phenomena (Nonacs 2017). Based on our results, the ability of workers to activate their ovaries in foreign colonies lies in their ability to react to the social context. It seems that high reproductive potential constitutes a key parameter promoting the acquisition of a parasitic phenotype in foreign queenright colonies. Similar outcomes were reported in workers in other eusocial insects. Bumblebee workers with active ovaries introduced into a foreign nest maintained their fertility, despite more frequent direct contacts with the queen and the brood than control workers. Conversely, infertile workers failed to develop a reproductive phenotype in a foreign nest (Yagound et al. 2012; Blacher et al. 2013). The study of intraspecific worker parasitism in the common wasp Vespula vulgaris showed that in foreign queenright colonies, drifters activated their ovaries at a rate that was ca. five times higher than the natal workers (Oliveira et al. 2016).

Another likely explanation for ovary activation by rebels in foreign queenright colonies is their greater learning ability. Learning allows individuals to adjust their behaviour to changing environmental conditions (Dukas 2008), which can have a considerable positive impact on individual fitness components. According to a recent study (Kuszewska and Rojek 2021), rebel workers learn faster than normal workers. As a result, the rebel workers in our 
study learned colony recognition cues before they were experimentally introduced on the 5th day of adult life to the foreign colony, which enabled them to detect changes in the colony and adjust their ovarian development, while normal workers presumably did not. However, we cannot exclude the alternative scenario in which normal workers detect themselves as being in a foreign queenright colony as rebel workers do, but they do not activate their ovaries due to lower physiological abilities or a longer time needed for activation. Some studies have shown that ovary activation is related to the number of ovarioles (Makert et al. 2006), and bees with more ovarioles are most likely to activate their ovaries (Amdam et al. 2006; Linksvayer et al. 2009; Wang et al. 2010; Traynor et al. 2014).

Interestingly, none of the groups of workers activated their ovaries after introduction into foreign colonies on the 1st day of adult life, which suggests that these workers did not recognize the change in the colony. Although some studies have shown that the recognition cue is acquired prior to emergence as an adult (Breed 1983), the experiments described in this paper support the hypothesis that the cue has an environmental, rather than a genetic, origin (Downs and Ratnieks 1999; D'Ettorre et al. 2006; Vernier et al. 2020). As the workers in our study were introduced to foreign colonies directly after emerging in the incubator, they probably recognized this colony as their own. Only after the 5 th day of being in a given colony were they able to recognize whether the colony had changed. There might be no adaptation to emerge in foreign nests.

In conclusion, in our experiment, the rebels responded to finding themselves in a foreign queenright colony by activating their ovaries, while the normal workers did not employ such a strategy. This finding suggests that the particular reproductive potential of workers may be a prerequisite for ovary activation in drifting behaviour and that rebels with high reproductive potential are more predisposed than normal workers to function as reproductive parasites in conspecific colonies.

Acknowledgements We thank Michal Woyciechowski for his suggestions and comments. We thank American Journal Experts for language editing (Certificate Verification Key: 7C6B-2835-EC70-11DB-465P).

Author contributions All authors contributed to the study conception and design. WR performed the experiments. All authors analysed the data. The first draft of the manuscript was written by WR, and all authors commented on previous versions of the manuscript. All authors read and approved the final manuscript.

Funding This study was funded by the National Science Centre (NCN) of Poland (grant 2016/23/B/NZ8/00803) and Jagiellonian University (grant DS/BiNoZ/INoŚ/2019-2021). The funders had no role in the study design, data collection and analysis, decision to publish, or preparation of the manuscript.
Data availability The datasets generated and/or analysed during the current study are available from the corresponding author on reasonable request.

\section{Declarations}

Conflict of interest The authors declare that they do not have any conflicts of interest.

Code availability Not applicable.

Open Access This article is licensed under a Creative Commons Attribution 4.0 International License, which permits use, sharing, adaptation, distribution and reproduction in any medium or format, as long as you give appropriate credit to the original author(s) and the source, provide a link to the Creative Commons licence, and indicate if changes were made. The images or other third party material in this article are included in the article's Creative Commons licence, unless indicated otherwise in a credit line to the material. If material is not included in the article's Creative Commons licence and your intended use is not permitted by statutory regulation or exceeds the permitted use, you will need to obtain permission directly from the copyright holder. To view a copy of this licence, visit http://creativecommons.org/licenses/by/4.0/.

\section{References}

Amdam GV, Csondes A, Fondrk MK, Page RE Jr (2006) Complex social behaviour derived from maternal reproductive traits. Nature 439:76-78

Beekman M, Oldroyd BP (2008) When workers disunite: Intraspecific parasitism by eusocial bees. Annu Rev Entomol 53:19-37

Blacher P, Yagound B, Lecoutey E et al (2013) Drifting behaviour as an alternative reproductive strategy for social insect workers. Proc R Soc B Biol Sci. https://doi.org/10.1098/rspb.2013.1888

Bourke AFG (1988) Worker reproduction in the higher eusocial Hymenoptera. Q Rev Biol 63:291-311. https://doi.org/10.1086/415930

Breed MD (1983) Nestmate recognition in honey bees. Anim Behav 31:86-91. https://doi.org/10.1016/S0003-3472(83)80176-6

Breed MD (1998) Recognition pheromones of the honey bee. Bioscience 48:463-470. https://doi.org/10.2307/1313244

Breed MD, Diaz PH, Lucero KD (2004) Olfactory information processing in honeybee, Apis mellifera, nestmate recognition. Anim Behav 68:921-928. https://doi.org/10.1016/j.anbehav.2003.10.033

Châline N, Sandoz JC, Martin SJ et al (2005) Learning and discrimination of individual cuticular hydrocarbons by honeybees (Apis mellifera). Chem Senses 30:327-335. https://doi.org/10.1093/ chemse/bji027

Chapman NC, Nanork P, Gloag RS et al (2009) Queenless colonies of the Asian red dwarf honey bee (Apis florea) are infiltrated by workers from other queenless colonies. Behav Ecol 20:817-820. https://doi.org/10.1093/beheco/arp065

Chapman NC, Beekman M, Oldroyd BP (2010) Worker reproductive parasitism and drift in the western honeybee Apis mellifera. Behav Ecol Sociobiol 64:419-427. https://doi.org/10.1007/ s00265-009-0858-7

Couvillon MJ, Caple JP, Endsor SL et al (2007) Nest-mate recognition template of guard honeybees (Apis mellifera) is modified by wax comb transfer. Biol Lett 3:228-230. https://doi.org/10.1098/rsbl. 2006.0612 
D’Ettorre P, Wenseleers T, Dawson J et al (2006) Wax combs mediate nestmate recognition by guard honeybees. Anim Behav 71:773779. https://doi.org/10.1016/j.anbehav.2005.05.014

Downs SG, Ratnieks FLW (1999) Recognition of conspecifics by honeybee guards uses nonheritable cues acquired in the adult stage. Anim Behav 58:643-648. https://doi.org/10.1006/anbe.1999.1177

Dukas R (2008) Evolutionary biology of insect learning. Annu Rev Entomol 53:145-160

Hamilton WD (1964) The genetical evolution of social behavior. II. J Theor Biol 7:17-52. https://doi.org/10.4324/9780203790427-5

Huang ZY, Otis GW (1989) Factors determining hypopharyngeal gland activity of worker honey bees (Apis mellifera L.). Insectes Soc 36:264-276. https://doi.org/10.1007/BF02224880

Jay CS (1965) Drifting of Honeybees in commercial apiaries 1. Effect of various environmental factors. J Apic Res 4:167-175

Kuszewska K, Rojek W (2021) Honeybee workers with higher reproductive potential have a greater learning ability. Apidologie. https://doi.org/10.1007/s13592-021-00847-9

Kuszewska K, Woyciechowski M (2015) Age at which larvae are orphaned determines their development into typical or rebel workers in the honeybee (Apis mellifera L.). PLoS ONE 10:1-12. https://doi.org/10.1371/journal.pone.0123404

Kuszewska K, Miler K, Rojek W et al (2018) Rebel honeybee workers have a tendency to become intraspecific reproductive parasites. Ecol Evol 8:11914-11920. https://doi.org/10.1002/ece3.4647

Kuszewska K, Wącławska A, Woyciechowski M (2018) Reproduction of rebel workers in honeybee (Apis mellifera) colonies. Apidologie 49:162-171. https://doi.org/10.1007/s13592-017-0537-z

Linksvayer TA, Rueppell O, Siegel A et al (2009) The genetic basis of transgressive ovary size in honeybee workers. Genetics 183:693707. https://doi.org/10.1534/genetics.109.105452

Makert GR, Paxton RJ, Hartfelder K (2006) Ovariole number-a predictor of differential reproductive success among worker subfamilies in queenless honeybee (Apis mellifera L.) colonies. Behav Ecol Sociobiol 60:815-825. https://doi.org/10.1007/ s00265-006-0225-x

Miller DG, Ratnieks FLW (2001) The timing of worker reproduction and breakdown of policing behaviour in queenless honey bee (Apis mellifera L.) societies. Insectes Soc 48:178-184. https:// doi.org/10.1007/p100001762

Moritz RFA, Neumann P (2004) Differences in nestmate recognition for drones and workers in the honeybee, Apis mellifera (L.). Anim Behav 67:681-688. https://doi.org/10.1016/j.anbehav.2003.08.004

Nakaoka T, Takeuchi H, Kubo T (2008) Laying workers in queenless honeybee (Apis mellifera L.) colonies have physiological states similar to that of nurse bees but opposite that of foragers. J Insect Physiol 54:806-812. https://doi.org/10.1016/j.jinsphys.2008.02. 007

Nanork P, Paar J, Chapman NC et al (2005) Asian honeybees parasitize the future dead. Nature 437:829. https://doi.org/10.1038/437829a

Nanork P, Chapman NC, Wongsiri S et al (2007) Social parasitism by workers in queenless and queenright Apis cerana colonies. Mol Ecol 16:1107-1114. https://doi.org/10.1111/j.1365-294X.2006. 03207.x

Neumann P, Moritz RFA (2002) The Cape honeybee phenomenon: the sympatric evolution of a social parasite in real time? Behav Ecol Sociobiol 52:271-281

Nonacs P (2017) Go high or go low? Adaptive evolution of high and low relatedness societies in social Hymenoptera. Front Ecol Evol 5:1-13. https://doi.org/10.3389/fevo.2017.00087
Oliveira RC, Oi CA, Vollet-Neto A, Wenseleers T (2016) Intraspecific worker parasitism in the common wasp, Vespula vulgaris. Anim Behav 113:79-85. https://doi.org/10.1016/j.anbehav.2015.12.025

Paar J, Oldroyd BP, Huettinger E, Kastberger G (2002) Drifting of workers in nest aggregations of the giant honeybee Apis dorsata. Apidologie 33:553-561. https://doi.org/10.1051/apido

Page RE, Metcalf RA, Metcalf RL et al (1991) Extractable hydrocarbons and kin recognition in honeybee (Apis mellifera L.). J Chem Ecol 17:745-756. https://doi.org/10.1007/BF00994197

Pfeiffer KJ, Crailsheim K (1998) Drifting of honeybees. Insectes Soc 45:151-167. https://doi.org/10.1007/s000400050076

Pirk CWW, Neumann P, Hepburn R (2007) Nestmate recognition for eggs in the honeybee (Apis mellifera L.). Behav Ecol Sociobiol 61:1685-1693. https://doi.org/10.1007/s00265-007-0399-x

Ratnieks FLW, Visscher PK (1989) Worker policing in the honeybee. Nature 342:796-797

Schlaepfer MA, Runge MC, Sherman PW (2002) Ecological and evolutionary traps. Trends Ecol Evol 17:474-480. https://doi.org/10. 1016/S0169-5347(02)02580-6

Smith ML, Loope KJ (2016) Caught in an evolutionary trap: worker honey bees that have drifted into foreign colonies do not invest in ovary activation. Insectes Soc 63:61-65. https://doi.org/10.1007/ s00040-015-0434-2

Traynor KS, Le Conte Y, Page RE (2014) Queen and young larval pheromones impact nursing and reproductive physiology of honey bee (Apis mellifera) workers. Behav Ecol Sociobiol 68:2059-2073. https://doi.org/10.1007/s00265-014-1811-y

van Zweden JS, d'Ettorre P (2010) Nestmate recognition in social insects and the role of hydrocarbons. Insect Hydrocarb Biol Biochem Chem Ecol. https://doi.org/10.1017/CBO9780511711909. 012

Vernier CL, Krupp JJ, Marcus K et al (2019) The cuticular hydrocarbon profiles of honey bee workers develop via a socially-modulated innate process. Elife 8:1-27. https://doi.org/10.7554/eLife.41855

Vernier CL, Chin IM, Adu-Oppong B et al (2020) The gut microbiome defines social group membership in honey bee colonies. Sci Adv 6:1-10. https://doi.org/10.1126/sciadv.abd3431

Wang Y, Kaftanoglu O, Siegel AJ et al (2010) Surgically increased ovarian mass in the honey bee confirms link between reproductive physiology and worker behavior. J Insect Physiol 56:1816-1824. https://doi.org/10.1016/j.jinsphys.2010.07.013

Wilson EO (1971) The insect societies. Belknap Press, Cambridge

Winston M (1987) The biology of honeybee. Harvard University Press, Cambridge

Woyciechowski M, Kuszewska K (2012) Swarming generates rebel workers in honeybees. Curr Biol 22:707-711. https://doi.org/10. 1016/j.cub.2012.02.063

Woyciechowski M, Łomnicki A (1987) Multiple mating of queens and the sterility of workers among eusocial hymenoptera. J Theor Biol 128:317-327. https://doi.org/10.1016/S0022-5193(87)80074-7

Woyciechowski M, Kuszewska K, Pitorak J, Kierat J (2017) Honeybee worker larvae perceive queen pheromones in their food. Apidologie 48:144-149. https://doi.org/10.1007/s13592-016-0459-1

Yagound B, Blacher P, Chameron S, Châline N (2012) Social context and reproductive potential affect worker reproductive decisions in a eusocial insect. PLoS ONE 7:1-7. https://doi.org/10.1371/ journal.pone.0052217

Yagound B, Duncan M, Chapman NC, Oldroyd BP (2017) Subfamilydependent alternative reproductive strategies in worker honeybees. Mol Ecol 26:6938-6947. https://doi.org/10.1111/mec.14417 